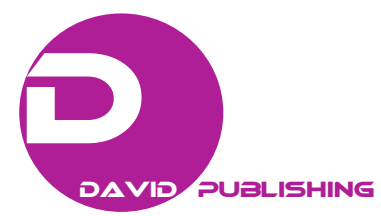

\title{
Modelling and Sporting Performance in Karate
}

\author{
Jérôme Frigout $^{1}$, Renaud Laporte ${ }^{1}$ and Angeline Lepresle ${ }^{2}$ \\ 1. Department of Sports Science and Physical Education, University of Paris Descartes, Paris 75015, France \\ 2. Departmental Committee of Val-de-Marne, French Karate Federation and Associated Disciplines, Créteil, Val-de-Marne 94000, \\ France
}

\begin{abstract}
Karate is a competition combat sport that will be present at the Olympic Games during the trials in Tokyo in 2020. Within its inner logic, this activity implies a system of scores that may lead to a specific modelling, to be unveiled and used when dealing with the search for performance. If we consider that various strategies all seem to be able to lead to victory within that zero-sum game, might there be a possible Nash equilibrium to look for, aiming at favouring some of them and minimising gains and losses? Must one privilege offensive or defensive behaviours, provoke or wait? In relation to new sporting rules, 309 combats have been observed in the light of their system of scores and our result reveal perspectives for training. Even though the results remain questionable and are still to be completed, they enable us to highlight propositions as to a modelling through the work of Biéchy. The suboptimal equilibrium thus highlighted reminds us that this game remains solely based on a system of rivalry, within which predefined strategy and initiative are to be articulated.
\end{abstract}

Key words: Karate, modelling, inner logic, strategy, system of scores.

\section{Introduction}

Karate is a Japanese traditional martial art. It is also a sports discipline that will accede to the Olympic programme for the first time at the Games in Tokyo in 2020.

According to the arbitration Rules of the French Federation of Karate and Associated Disciplines [1], this combat practise is supervised by a central referee who attributes penalties, and four corner judges who state scored points. In case of a draw at the end of regulatory time, the five of them attribute a flag vote to the winner (fighting spirit and strength, tactical and technical superiority, initiative in actions). To validate a point, four criteria must at first be put together (efficiency potential, alertness, timing, distance) and at least two flags must be raised to the colours of protections (blue or red). Thus the four judges can simultaneously validate points to each fighter (for example: two flags for blue $-a o$, and two flags for red - aka). Penalties (category one for excessive contacts

Corresponding author: Jérôme Frigout, Ph.D., sport manager, research fields: karate and aggressiveness, modelling and performance in karate. and category two for prohibited behaviours) can be attributed by the central referee, who then asks to be confirmed by the four corner judges. Points and penalties are given during fight breaks, resulting in a fractioning of the fight, with the fighters returning to a waiting position before restarting. If eight points separate the two fighters, the fight is ended and victory goes to the one having the highest number of points.

Three additional elements are to be kept in mind: the ten second rule enables the referees' group to interpret - according to the criteria - if a given blow, which has put one of the two adversaries down and unable to get up, must lead to a category one penalty or to the attribution of points (with a category 2 penalty for the knocked out fighter). On the other hand, the use of video replay enables the trainer, who is placed in the corner of his fighter, to ask for a revision of an arbitral decision and to get a point validation, disregarding the observation and validation of the judges. Finally, the rule of senshu (the advantage goes to the first fighter who has scored in case of a draw at the end of regulatory time), which is currently under trial in internationally referenced competitions, has just been 
introduced for the very first time during the Open of Paris-Karate Premier League 2017, which took place from January 27th to 29th at the Pierre de Coubertin stadium.

Maai, meaning spatial distance [2], understood here between fighters, and yoshi, referring to pace/rhythm [3], are the two elemental lines in the practise of that sport.

We believe it is necessary $[4,5]$ to consider that an analysis and observation of performance lead to a stance that brings us to consider that in combat disciplines, and in karate in particular, the dimension of the technical and tactical paradox weighs up the notions of "exposure, realism, self-protection, creativity" [5], hence the pregnance of tactical, informational, psychological and technical factors.

Here is the pattern of performance, in other words the priorities in karate practise: time is the first priority (strategic, tactical, bio-informational factors), moves are the second priority (psychological and bio-mechanical factors), and technique is the last priority (bio-mechanical, bio-energetic, bio-anthropomorphic factors).

\subsection{Observing Karate}

In the realm of competitions and karate meetings, we keep hearing injunctions from trainers to their fighters: gyaku! (back punch), one-two! (action that is cyclic or achieved as a secondary attack intention), mawash'! (circular kick), etc. Are these actions reflecting the actual opportunities a sportsman has to perform a socio-motive skill during the exchange of combat, or rather the vision the trainer wishes to embrace? It is often something (s)he cannot perform, as (s)he has not automated it enough.

Jacques Piasenta [6], an athletic trainer, illustrates well our words: "On the field, I have come to clearly perceive, with an obvious acuity, what I could not see some years ago. This observation has convinced me that everyday, some forms of athletic behaviours unfold in front of which I remain blind, and it keeps fascinating me."

In that perspective, what are the obstacles linked to observation, according to Piasenta [6]? Several elements are to be mentioned:

- we are only able to perceive what concerns or fascinates us;

- professional quirk, because of which we only perceive what we are familiar with;

- specificity of the aptitude to observe: immediacy;

- first we find, then we search.

Jacques Piasenta, an unwilling Parlebasian, incites us to reflect upon the notions of gestèmes (motive behaviours) and praxèmes (tactic behaviours) [7], their codes [8] and their practical use in the service of practise. In the same way, his work dealing with observation leads us to investigate how communication and counter communication have to be studied in that perspective. Under those circumstances, gestèmes ("gestures through which a player transmits an indication"), praxèmes ("motor behaviour (...) liable to be interpreted"- - a signifier as much as a signified) and communication processes may integrate sportive planning and programming, within a modelling whose existence and relevance are left to be verified.

The analysis of data taken from video observation aims at understanding, in a specific set of rules, how to express and oppose oneself in front of an opponent. In karate, it means dealing, within a given time and space, with an opponent who can be granted a maximum of one point or one flag less than oneself. On top of that, risk-taking and self-confidence have to be carefully balanced in order to avoid a possible knock out.

\subsection{Karate and Modelling}

According to Barbut [9] and Parlebas [10], each phenomenon, whether social or natural, and here karate, has to offer a theory concerning its own praxis. If it withstands the scientific process of demonstration through evidence, that theory might then engage in the search for its modelling.

For the trainer, how to make the choice of a 
methodology targeted to strategic training to competition, and establish various patterns of tactical adaptation? Is it necessary to refrain from spectacular features with a strategy based on relative caution (provocation to work in parry response) and get recognition as, Nadège Ait-Ibrahim did during the World Championship in 2012? On the contrary, should a bold strategy be adopted (with an attack in two or even one intent), which led Steven Da Costa to the European title in 2014 thanks to three kicks to the face (while being swept thrice)? Finally, is it better to force oneself to impose nothing, and get back to the training to the four key elements [5], following Rafael Aghayev?

The search for simultaneousness in the validation of points may be an option aiming at minimising gains in order to minimise losses. However, at this stage, the lack of research and statistical data does not allow us to confirm or refute whether the Nash equilibrium [11] or the defensive theory of Clausewitz [12] may apply and model practise.

Parlebas [13] introduces what he calls the universals as elements of a possible modelling. Those ones call to mind - here, the reader and on the ground, the trainer and the trainee. That designation implies the existence of a form of organisational logic specific to each activity, which he names inner logic.

We tend to think that the system of scores is part of the points that, in terms of performance, can unveil trends in the practise and recommendations to follow for the trainer. Parlebas introduced and defined in karate the motive communication networks, the forms of marking interaction [13], and the spaces and times of practise. When we put all these parameters together and put them in the light of observations taken from fights, can they lead us to improve the training of sportsmen?

We consider the idea that this discipline may not avoid that formalisation, and that the studied observations could, as Parlebas [13] tells us, lead us to:

- A simplified and formalised description of the studied situation.

- An operational simulation that would reveal an operating dynamic.

- A formalisation that would enable an objective processing of data, and possibly a prediction.

- The possibility to apply testing on field situations.

To this point, we can notice a parallel between Piasenta and Parlebas when it comes to their respective work. Considering observation and modelling, the first leads us to the second, in order to give new perspectives to science, teaching and management of motive action.

In this regard, from an oulipo $[14,15,16,17]$ to an oulupo, the latter offering to "invent new rules susceptible to be formalised" [13], is it possible to achieve the goal of wiping out the uncertainty of a result in a karate combat?

\subsubsection{Possible Simultaneousness of Touches}

It is important to remind that the inner logic of sports games reveals the following network concerning exclusive dual sports: $\mathrm{R} \cap \mathrm{S}=\varnothing[18]$. This network reminds us that two karatekas fighting each other cannot be at the same time rivals and partners. That type of game in which the system of scores is strictly antagonistic [13] is expressed according to the formula $\mathrm{M}+=\varnothing$. As a competitive activity, karate is a zero-sum game [19]. Each combatant, in his/her wish to win a combat, has to assert his/her interests to the detriment of those of his/her opponent. Formalising that constraint for competitors in karate comes back to presenting a sum of two functions that is always equal to 0 .

Even though the issue might seem irrelevant, Clausewitz, in "De La Guerre", gives an advantage to defence. That theory, inspired from the Roman limes (a fortified border with forts placed at the front of the defence line itself), was expressed at the outcome of Napoleonic campaigns and it seems to favour the idea of an active form of defence. Would it be possible to consider, as written above, that this model, applied to karate, enabled Ait-Ibrahim to win the title of World 
Champion in the $+68 \mathrm{~kg}$ category in 2012 ? Indeed she won the final thanks to a work of provocation (gestèmes) and pressure (praxèmes) while avoiding any spectacular moves.

If we attempt to go further, do we have to consider using the work of Nash dealing with the equilibrium between gains and losses? As Nash put it [11], "the pay-off functions are the expectations of the players, thus becoming polylinear forms in the probabilities with which the various players play their various pure strategies." He thus demonstrates that there is no equilibrium in pure strategy, and that, as a consequence, a recourse to probabilities is needed, and therefore a mixed strategy.

As a consequence, we can wonder whether at least a Nash equilibrium may exist in karate, that is to say a situation in which no player would have an interest in changing unilaterally his/her fight strategy. Pure strategy is at stake in the case of a combatant who determines his/her own strategy. However, karate being a dual activity practised in situations of probability prospectives, mixed strategies may be a more appropriate expression (that is to say the sum of possible pure strategies). If there is an equilibrium, it will not be systematically optimal for each player simultaneously. Some strategies may indeed lead to superior gains, for one or the other adversary.

The Nash theorem can be summarised as follows: let $g: S 1 \times \ldots \times S m \rightarrow R m$ ( $R$ for result). A game (in which a player does not know the choices of his/her adversaries) in which $m$ represents the number of players and S1 the set of possibilities for the player i, and let $\bar{g}$ be the extension of $g$ to mixed strategies. Then, the game $\bar{g}$ accepts at least one point of equilibrium.

In virtue of an arbitration system allowing a simultaneous marking of both fighters, should a karateka attack (widen the gap and take the risk of being countered or put away), settle for countering the initiative of an adversary that (s)he has provoked to attack (and thus validate points by simultaneousness), or else push the adversary into attacking and get opportunities for indirect defences (absorption followed by a return of attack)? Or else, depending on the moments and configurations of the fight, is it accurate to combine those various possible modes of point scoring, and thus integrate the adversary equation in that pattern of possible responses (who is (s)he? - what is (s)he doing?)?

A fighter trains to win with a lead of a single point or flag on his/her adversary in a strictly antagonistic system of scores, in which points may however be scored simultaneously by both adversaries, and thus the question of a possible balance between gains and losses may be raised.

\subsubsection{Senshu}

From January 27th to January 29th, 2017, the World Karate Federation established a new arbitration directive, during the Open of Paris-Karate 1 Premier League: the first point to be scored gets priority and grants victory to the one who scored it in case of a draw at the end of regulatory time.

The question to be raised here is that of the assumed advantage for offensive. However, with a more cautious analysis, senshu does not favour the most offensive behaviour, even though it is the wish of the World Karate Federation, hoping to avoid lengthy periods of observation between fighters at the beginning of a match. It only favours the first fighter who scores, in his/her pre-established strategic choice. As already mentioned, points can be scored in attack, direct defence or indirect defence. Nash [11] invites us to wonder to what extent it is necessary for players to find a solution such that no player would have an interest in changing tactics if the other maintains his/hers.

Thus, in relation to that specific arbitration point, trainers and fighters would be wise not to mistake offensive for taking of initiative. That taking of initiative to carry out a strategy is not necessarily synonymous with choosing the role of the attacker. Therefore, it is important to focus on the notions of 
decision-taking and rationality [20, 21], and also hoped-for utility [22]. All this is about the concepts and possible scopes of intervention developed in the theory of games $[22,23]$.

On top of that, we know that, despite the rule of senshu, two possible cases of scores lead to a flag vote at the end of regulatory time, that is to say the case of a 0/0 score, and the case in which the two fighters score the first point simultaneously. That new system has the merit of opening the way for reflexion for the trainer/trainee couple about the scoring of the first point, but it will not necessarily encourage all karatekas to turn into constant attackers.

\section{Material and Methods}

Observations were carried out by sports instructors (holders of federal and state degrees) during the official match records of the FFKDA, between January 24th, 2016, and January 29th, 2017.

The observations were carried out during six distinct competitions, comprising various publics, such as children, teenagers, adults and veterans (up to more than 55 years old) of both sexes. A very significant proportion of international athletes, including the eight best world fighters of each weight category of both sexes in the last world championship (Linz, 2016) were observed, with a total of 191 fights. Added to them were 118 children, teenage and veteran fighters of both sexes. In total, 148 male fights and 161 female fights were observed. A total of 618 observations in 309 fights were carried out with competitors in situations of fight.

The observations concerned the system of scores and more particularly what judges and referees validated: date, location of the event, observer, category (age, gender, weight), held belt (blue or red), scored points (simultaneously or separately), possible gained flags (in the case of a score draw at the end of regulatory time), total amount of scored points, senshu (priority to the first scored point).
The statistical processing of the data was carried out with the Sphinx IQ2 software, which processes quantitative surveys.

The observations carried out during the practise of the above-mentioned publics enable to discriminate whether the system of scores can significantly model competitive karate practise and the search for performance, and will have to lead trainers and sportsmen to include additional data to the act of training according to a model of performance and regular observations: those linked to the inner logic of the activity and its effects in order to win with a lead of one point or flag.

\section{Results}

The results presented in the following tables report the number of involved fighters. The loser is stated before the / symbol, and the winner is stated after.

Yuko means punch, waza ari means kick to the body, and ippon means kick to the face (except ippon scored by sweeping).

Each technique brings its share of different points, but we can observe that punches and face kicks validate 4/5th of scored points, and sweeping actions only stand for a tiny percentage of the total scored points.

The results presented above show an average of 2.84 points scored by combat, i.e. 1.42 point per fighter (Table 1).

We can also notice that the small number of points scored simultaneously makes these results non-significant, compared to the totality of scored points in the totality of competitions and fights that were observed (Table 2).

Before the application of the senshu rule, we can notice: only one victory won thanks to flags with a 0-0 score, and only one victory won thanks to flags with an $\mathrm{x}$-x score. With the senshu rule: 0 victory won thanks to flags with a 0-0 score, and 9 victories won thanks to senshu with an $\mathrm{x}-\mathrm{x}$ score (Table 3 ). 
Table 1 Recap chart of scored points in percentage.

\begin{tabular}{llllll}
\hline Type of action & Value in points & $\begin{array}{l}\text { Number of } \\
\text { occurrences }\end{array}$ & Total point value & $\begin{array}{l}\text { General total of } \\
\text { scored points }\end{array}$ & $\begin{array}{l}\text { Expression in } \\
\text { percentage }\end{array}$ \\
\hline Yuko & 1 & 384 & 384 & $43.735 \%$ \\
Waza ari & 2 & 67 & 134 & 878 & $15.261 \%$ \\
Ippon & 3 & 111 & 333 & & $37.927 \%$ \\
Ippon bal. & 3 & 9 & 27 & $3.075 \%$ \\
\hline
\end{tabular}

Table 2 Points scored simultaneously connected to victory.

\begin{tabular}{|c|c|c|c|c|}
\hline Points & 0 & 1 & 2 & $P$ \\
\hline \multirow{2}{*}{ Yuko } & $295 / 292$ & $11 / 13$ & $3 / 4$ & \multirow{2}{*}{$P=0.85$} \\
\hline & NS & NS & NS & \\
\hline Waza ari & $\begin{array}{l}307 / 309 \\
\text { SS }\end{array}$ & $2 / 0$ & & $P=0.16$ \\
\hline Ippon & $\begin{array}{l}307 / 309 \\
\text { NS }\end{array}$ & $\begin{array}{l}2 / 0 \\
\text { NS }\end{array}$ & & $P=0.16$ \\
\hline Ippon bal. & & & & $\varnothing$ \\
\hline
\end{tabular}

Table 3 Victories acquired with flags and cases of senshu connected to victory.

\begin{tabular}{llllllll}
\hline Rule & 0 & 1 & 2 & 3 & 4 & 5 & $P$ \\
\hline \multirow{2}{*}{ Flags } & $302 / 292$ & $3 / 0$ & $4 / 0$ & $0 / 4$ & $0 / 3$ & $0 / 10$ & $P \leq 0.01$ \\
\hline \multirow{2}{*}{ Senshu } & TS & TS & TS & TS & TS & TS & $P=0.01$ \\
\hline
\end{tabular}

\section{Discussion}

Questioning the system of scores, which is the cornerstone of competition, enables us to understand how inner logic can influence motor conducts, regarding a competition and its results.

Various profiles of fighters are likely to win and have done so on several occasions, whether offensive, defensive or countering types. With their trainers, all of them attempt to interpret and live the rule, as fairly and closely as possible.

Karate is a zero-sum sports game [13, 19], but it can also allow, in given conditions, to practise according to a cautious strategy, based on acute observation and wait-and-see attitude towards adverse productions. The attempt to minimise gains in order to minimise losses then amounts to define an essentially defensive strategy. Is that possible?

If it is admitted that such an exercise already enabled an athlete to rise to the highest level in a world championship (Ait-Ibrahim in 2012) or a continental one (Florentin in 2017), that is to say a
Nash equilibrium [11] is made possible between two aggressive strategies in a zero-sum game, its result is nevertheless considered sub-optimal [13] in the theory of games.

Indeed, two rules in karate competition cause a non-significance in terms of cooperative strategies: first, fight interruptions to attribute points to the first fighter who scored is seen as a significant norm, contrary to the simultaneous marking of scores, of which a too small amount was observed to draw a useful modelling for trainers and athletes. The acquisition of points during simultaneous actions does not guarantee victory in a fight, and it can even be the contrary, but too few cases could be observed for that observation/conclusion to be significant. Then, the introduction of the senshu rule, even though it does not seem to have deeply modified the behaviour of competitors, leading them to become constant attackers, has not either allowed strategic behaviours aiming at waiting for a draw at the end of a fight in order to get a vote and flag decision from the judges.

The low number of points which are scored on 
Table 4 Interpretation of the four propositions of Biéchy in the frame of possible strategies in karate.

\begin{tabular}{llll}
\hline Aka versus Ao & Attacker & Defender & Counterer \\
\hline Attacker & Exposing versus exposing & Creativity versus protecting & Creativity versus exposing \\
Defender & protecting versus creativity & Realism versus realism & Realism versus protecting \\
Counterer & exposing versus creativity & protecting versus realism & protecting versus protecting \\
\hline
\end{tabular}

average in a fight should not conceal the numerous exchanges between fighters: numerous attempts are led between adversaries, and the situations introduced by Bléchy [5] have been observed: "realism, creativity, exposure and self-protection." Points were scored in attack, defence, countering, and a very low number simultaneously.

Therefore, from Parlebas to Nash, which trend would be best to follow: offensive, or on the contrary caution and a defensive organisation, as defined by Clausewitz? Are various patterns of fight to be allowed in order to make the opponent change his/her strategies? Should a fighter constrain him/herself to never change his/her strategy during a combat? When at risk, how can decisions be taken by a competitor [20]?

In this context, producing a performance amounts to surprising an opponent and preventing him/her from adapting to a strategy which is brought to completion, while revealing it as late as possible. Nevertheless, the sub-optimal result in the Nash equilibrium in karate does not mean that only offensive aggressive behaviours can lead to victory. The average number of points scored in a fight does not mean either that a fighter cannot win before the end by getting an interval of 8 points with his/her opponent. The latter might also be disqualified following category 2 penalties, or get knocked out within the rule. Would Aghayev, still Aghayev, be the example to follow, that is to say to have no restriction? And thus, from those observations, to come back to practise in order to better combine its benefits with those of observation and of the accurate knowledge of the system of scores and its productions. Following the work of Biéchy [5], we may raise the following hypothesis, as a tool enabling understanding and adaptation to the opponent in karate fight (Table 4).

\section{Conclusion}

The results unveiled in this work are in a way complete as they enable to understand that an equilibrium between gains and losses is not relevant in karate competition. However, they are also incomplete considering the breach they open concerning the complementary information (that is) necessary to define more precisely that modelling and make it more accurate.

This work also leads us to keep considering that it is possible for each fighter and strategic model to find a place within that sport, even though the ultimate goal remains a domination and symbolic victory acquired with at least a lead of one point or flag. As a zero sum sports game [19], it therefore privileges contacts based on domination within the frame of its inner logic. As demonstrated by the results in this article, an arrangement leading to a draw (including team competition) does not seem to be possible anymore, considering the non-relevance of the rule of simultaneous marking, of the application of senshu and of the significant absence of draws ( $0-0$ or $\mathrm{x}-\mathrm{x}$ scores marked simultaneously).

Parlebas [8] shows us that understanding a sport within its inner logic enables “... to ensure $a$ permanent back and forth movement between the constraints of the structures and the fantasy of the players themselves." Shubik [21] also underlines that rationality is not always the remaining decision-took. In that sense, in karate, the Azeri fighter Rafael Aghayev does not remain a model but a reference to understand and exploit the universal elements in his discipline, as much as he is in his "ability to reveal emotions, the awareness and experience of players (...)" 
[8]. Karate is not "foolish and meaningless gesturing" [13], but it fits the criteria of a modelling as well as those of human sciences and biology, which define its model of performance and various constraints regarding charges.

However, the observations and conclusions presented here need further research, regarding the following elements: points, types of points and total number of scored points, category 1 and 2 penalties, victory or defeat (including before limit in the case of a gap of 8 points or more between fighters), potential disqualification, potential injury. Possible additional results might reveal, before taking into account the Olympics in 2020, new significances and be useful to trainers and athletes as much as to referees and organisers, as well as to optimise performance, to organise and manage the timing of the event to plan.

\section{References}

[1] French Karate Federation and Associated Disciplines (FFKDA). 2016. Arbitration Rules. Montrouge. (in French)

[2] Hall, E. T. 1971. The Hidden Dimension. Trad. fr. Paris: Seuil (1st ed. in English: 1966).

[3] Tokitsu, K. 1979. The Way of Karate. For a Theory of Japanese Martial Arts. Paris: Seuil. (in French)

[4] Fourré, M. 2003. Karate. Physical Preparation and Performance. Paris: INSEP. (in French)

[5] Biéchy, J.-P. 2012. Systemic Approach of Sporting Performance. Paris: Amphora. (in French)

[6] Piasenta, J. 1994. Learn to Observe. An Advocacy for Training in the Observation of Sporting Behaviour. Paris: INSEP. (in French)

[7] Parlebas, P. 1999. Games, Sports and Society, Lexicon of Motor Praxeology. Paris: INSEP. (in French)
[8] Parlebas, P. 2016. Traditional Games, Sports and Cultural Heritage. Culture and Education. Paris: L'Harmattan. (in French)

[9] Barbut, M. 2000. "Mathematics and Human Sciences. Sketch of a Balance Sheet." In The Actor and its Reasons. Blends in Honor of Raymond Boudon. Paris: Presses Universitaires de France, 205-24. (in French)

[10] Parlebas, P. 2010. "Mathematical Modeling, Sporting Games and Social Sciences." Mathematics and Human Sciences 191: 33-50. (in French)

[11] Nash, J. 1950. "Equilibrium Points in n-person Games." Proceedings of the National Academy of Sciences of the United States of America. National Academy of Sciences: 48-9.

[12] Clausewitz, C. V. 2014. Of the War. Trad. fr. Paris: Tempus (1st ed. in German: 1832).

[13] Parlebas, P. 2005. "Modelization in Games and Sports". Mathematics and Human Sciences 170: 11-45. (in French)

[14] Le Lionnais, F. 1971. "Alice Plays Chess." In Lewis Carroll ${ }^{\circ}$ 17. Paris: 1'Herne. 133-45. (in French)

[15] Queneau, R. 1961. One Hundred Thousand Billion Poems. Paris: Gallimard. (in French)

[16] Oulipo. 1973. The Potential Literature. Paris: Gallimard. (in French)

[17] Oulipo. 1981. Atlas of Potential Literature. Paris: Gallimard. (in French)

[18] Parlebas, P. 1986. Elements of Sociology of Sport. Paris: PUF. (in French)

[19] Rapoport, A. 1967. Combats, Games and Debates. Trad. fr. Paris: Dunod (1st ed. in English).

[20] Raïffa, H. 1968. Decision Analysis: Introductory Lectures on Choices Under Uncertainty. Addison-Wesley MA: Reading.

[21] Shubik, M. 1971. "The Dollar Auction Game: A Paradox in Non-Cooperative Behavior and Escalation." Journal of Conflict Resolution 15 (1): 109-11.

[22] Von Neumann, J., and et Morgenstern, O. 1944. Theory of Games and Economic Behavior. Princeton: University Press.

[23] Davis, M. 1970. Game Theory. New York: Dover Publications, inc. 